\title{
0 treino dos jovens desportistas. Actualização de alguns temas que fazem a agenda do debate sobre a preparação dos mais jovens.
}

\author{
António T. Marques \\ José Manuel Oliveira \\ Faculdade de Ciências do Desporto e de Educação Física, \\ Universidade do Porto
}

https://doi.org/10.5628/rpcd.01.01.130

\section{INTRODUÇÃO}

Os sistemas de treino e de competições dos mais jovens carecem de um maior aprofundamento. Os modelos explicativos existentes, desenvolvidos ao longo dos últimos quarenta anos, apoiam-se ainda muito na experiência e no conhecimento empírico, em orientações pedagógicas e normativas, e menos do que seria desejável na explicação científica $(23,24,27,28,29)$. A necessidade de qualificação da prática durante os anos de formação desportiva tem estimulado a reflexão e o debate dos especialistas de forma mais intensa nos últimos quinze anos. Desse debate, destacaríamos quatro pontos principais: a natureza dos exercícios de treino (2, 28, 29, 32, 38, 48, 49), a estrutura e a dinâmica da carga $(26,30,32)$, o desenvolvimento das capacidades motoras $(3,17,20)$ e o sistema de competições. Deste último não falaremos aqui, remetendo os interessados para alguns ensaios e estudos em que é tratado $(1,25,41,46)$.

\section{OS EXERCÍCIOS DE TREINO}

A Teoria dos Sistemas Funcionais de Anochin (cf. 48) remete para a necessidade de uma grande frequência e especificidade contextual de estímulos e feed-backs. A Teoria da Adaptação condiciona as possibilidades de adaptação do organismo às chamadas "reservas de adaptação".

Estes pressupostos determinariam que o espectro de factores a treinar estivesse limitado às exigências mais relevantes da estrutura do rendimento num determinado desporto. A não ser assim (Boiko, 1987, citado em 49) as possibilidades de adaptação do organismo diminuiriam perante o aumento do número de factores aos quais este se deveria adaptar. Isto é, um reforço da especialização desportiva e a consequente diminuição da diversidade dos estímulos conduziria a um aumento da prestação desportiva. Esta tese vem reforçar a ideia de que uma diminuição da quantidade de componentes do sistema motor-funcional activado conduziria a uma maior centração sobre as reservas de adaptação e, deste modo, a um desenvolvimento mais efectivo desse sistema.

Deste quadro teórico parte Tschiene (49) para questionar o sentido da estruturação do treino na inobservância das exigências específicas de um dado desporto. Ou seja, o autor pretende acentuar que, sendo a adaptação específica o princípio fundamental do funcionamento dos sistemas biológicos, o modelo de rendimento mais elevado deveria funcionar como um factor estruturante de todo o sistema de preparação desportiva, aí incluída a formação dos jovens desportistas.

Se relativamente à preparação dos atletas de alto nível já não se perde tempo a discutir esta questão, contestando-se abertamente o "princípio da unidade entre o treino geral e o treino especial”, na formação dos jovens desportistas ela não justifica o consenso. A questão da relação entre os exercícios gerais e especiais na preparação dos mais jovens é ainda um tema controverso entre os especialistas do treino. Aprofundemos o debate nas suas implicações. Anterior a toda a aquisição da estrutura complexa dos gestos e das acções desportivas está uma cultura motora não especializada, mais simples, constituída por um repertório de gestos e comportamentos motores. Sem a qual não se evoluirá, nem de forma eficiente, nem de forma estável, no aprofundamento do rendimento desportivo.

Este é um quadro perfeitamente aceite pelos 
especialistas, que assim reconhecem que a formação desportiva não se faz na dependência estreita, sistemática e exclusiva dos fundamentos da cultura da futura actividade especializada. E tampouco sem pôr em causa que os modelos mais avançados do desporto deverão funcionar como elementos estruturantes da formação dos jovens desportistas. Isto é, continuando a aceitar como válidos os princípios da especialização crescente e máxima no desporto de rendimento.

Que tipo de consequências daqui resultam para a nossa reflexão?

Em primeiro lugar, que haverá um momento em que a especialização se terá que fazer, questão esta que remete para o momento de início da especialização. Em segundo lugar, que a especialização não se fará em quaisquer condições. Ela será, por um lado, função do quadro concreto que a justifica em cada desporto, e, por outro lado, influenciada pelo quadro de vivências, aquisições, aprendizagem e desenvolvimento anterior dos jovens desportistas. A questão da idade de entrada em especialização desportiva é controversa, estando dependente das características do desporto escolhido, dos factores que influenciam o desenvolvimento de crianças e jovens e, sobretudo, da cultura desportiva dominante. Isto é, do quadro de condições que determinaram nos últimos quarenta anos o capital de conhecimento e experiência utilizado no enquadramento da preparação desportiva dos mais jovens. Objecto, embora, de uma grande reflexão teórica nos últimos anos, a resposta a esta questão não se faz simples do ponto de vista científico, continuando no fundamental a estar dependente de outros contributos.

A procura de soluções para a especialização em desporto determinou, é sabido, um início cada vez mais precoce das carreiras desportivas.

Acompanhando este processo foram desenvolvidos sistemas nacionais de competição e aperfeiçoadas as competições internacionais dos mais jovens.

O desenvolvimento das carreiras de atletas de alto nível, em vários desportos, permite perceber duas vias principais na construção a longo prazo da prestação desportiva (2):

(i) início em idades baixas da especialização num desporto, sendo que em alguns desportos isto se faz-se logo a partir dos 4 anos, embora na maior parte deles isso só venha a acontecer entre os $8 \mathrm{e}$ os 10 anos;

(ii) início em idade baixa (entre os 6 e os 12 anos) da prática de uma actividade desportiva regular diversificada, seguida da especialização num desporto (normalmente entre os 12 e os 15 anos) para o qual se manifestam condições de obtenção de sucesso.

O conhecimento da situação em vários países deixa perceber que vai prevalecendo a primeira via, isto é, que as crianças e jovens são orientados para o desenvolvimento de uma elevada especialização relativamente cedo.

A segunda questão relaciona-se com as condições em que se deve fazer a especialização.

Circunstâncias bem conhecidas, que não desenvolveremos aqui, têm determinado que as experiências motoras e desportivas dos mais jovens, na escola e fora desta, sejam cada vez mais pobres. Este facto constitui a razão fundamental para a diminuição das capacidades motoras de crianças e adolescentes.

Particularmente deficitárias são as vivências e aquisições no plano coordenativo-motor, aspecto essencial à capacidade de prestação desportiva. Para além de pôr em causa um normal desenvolvimento motor, a sua deficiente manifestação dificulta a aprendizagem e aperfeiçoamento das acções técnicas e diminui o potencial de utilização condicional. $\mathrm{O}$ que cria dificuldades acrescidas aos técnicos desportivos no momento da adopção de estratégias especializadas de preparação. E enfatiza a importância da valorização do treino geral - antes situado no âmbito de intervenção da escola e da actividade espontânea da criança - no quadro da formação desportiva especializada dos mais jovens. Esta situação vem dar força aos argumentos daqueles que afirmam o primado da formação multilateral de base como princípio director do treino na infância, fundados em razões da teoria pedagógica, da teoria do desenvolvimento e da metodologia do treino $(19,32)$. Num outro artigo (cf. 26) desenvolvemos estes aspectos.

Temos então, por um lado, que o sistema funcionalmotor forma-se especificamente e não em geral, 
segundo o princípio da replicação adequada e precisa de parâmetros espaciais, temporais e energéticos na interacção motora do indivíduo com o seu meio (49). Temos, por outro lado, a posição daqueles $(19,32,38)$ que defendem que isso é apenas válido em condições determinadas. Estas pressupõem, por um lado, a construção prévia dos factores sobre que assentará a estrutura especializada da actividade desportiva e, por outro lado, a neutralização ou minimização dos factores de impacte sobre a diminuição das condições da estabilidade e longevidade das carreiras desportivas. Por exemplo, a ocorrência de lesões resultantes da aplicação sistemática de cargas unilaterais/especializadas prematuramente (32), ou a repetida utilização das mesmas rotinas de treino, influenciando o abandono prematuro da actividade desportiva $(36,37,40)$.

Não se está perante um impasse, sequer perante a necessidade de conciliar posições que aparentemente não convergem. Trata-se de conformar a prática aos contributos científicos mais recentes, sem esquecer as novas realidades. Consagrando cumulativamente o princípio da orientação para um objectivo - a especialização num desporto - e o princípio da diversidade, sem que isso seja contraditório (38). Defende-se, não o abandono do treino geral nas estratégias de preparação, mas que este seja pensado em função da estrutura do rendimento de cada desporto. Que a natureza e a importância do treino geral sejam não apenas consideradas em função do estádio de desenvolvimento e da idade de treino de cada jovem desportista, mas também em função do quadro de condições concretas de cada desporto. Delimitando o conceito de multilateralidade especificamente para cada desporto (2), através de uma diversidade específica de cada desporto, em que os exercícios sejam dirigidos desde logo, quer na estrutura da carga, quer na estrutura motora, para o desporto escolhido (49). Promovendo uma formação multilateral específica, em que predomine a formação das capacidades técnico-coordenativas (38). Considerando que a adequação dos meios de treino geral poderá ser maior se a sua orientação for não apenas condicional, isto é energética e funcional, mas tiver uma direcção informacional e neuromotora cada vez mais acentuada (2). Nesta perspectiva, o princípio da especialização aplica-se também à utilização na formação desportiva dos meios de preparação geral. A crescente especialização a promover na preparação, dizendo respeito a todos os âmbitos do treino, é também extensível ao treino geral (38).

Começam já a surgir novas propostas e contributos de especialistas, ao encontro da necessidade de aplicação na prática do princípio da formação multilateral segundo os aspectos específicos do desporto. Através do ensaio de definição de um quadro criterial e organizativo dos exercícios gerais mais apropriado, função de cada desporto $(45,48)$. Peter Tschiene (48), particularmente, tem feito um esforço de reorganização e sistematização neste sentido, propondo a classificação dos exercícios de treino no desporto de crianças e jovens segundo:

(i) o grau de transferência motora relativamente aos exercícios de competição;

(ii) o grau de efeito funcional, em relação com o desenvolvimento biológico e a idade de treino dos jovens atletas;

(iii) a intensidade necessária de realização dos exercícios; e (iv) a estruturação dos exercícios segundo a idade.

\section{A CARGA DE TREINO}

A Teoria do Treino não desenvolveu ainda um modelo teórico de enquadramento da carga nos diferentes estádios da preparação dos mais jovens (32). A intervenção dos treinadores tem sido, no essencial, suportada por alguns princípios e orientações normativas. Como orientação fundamental, todas as componentes da carga (volume, frequência, densidade, intensidade) devem aumentar gradualmente com a idade de preparação, em acordo com os princípios do aumento sistemático da carga e da individualidade. Como orientação complementar, no aumento das componentes da carga a primazia deve ser dada ao volume; significando isto que, no controlo da dinâmica da carga, a quantidade deve crescer mais rapidamente que a intensidade.

O que é pouco, manifestamente.

Durante muito tempo, associou-se o aumento do rendimento ao número de anos de preparação desportiva, na convicção de que do aumento do tempo 
de treino e do número de anos consagrado à formação resultaria um claro aumento da prestação (5).

Hoje, repensa-se a formação desportiva à luz do fracasso de estratégias deste tipo e de consequências a outros níveis. O aumento substancial do tempo consagrado à preparação dos mais jovens está a prejudicar, em momentos em que a preparação ainda não é decisiva, o tempo que deveria ser dedicado a outras actividades educativas e formativas, incluindo a própria escola. Exigências elevadas de preparação estão a repercutir-se negativamente na própria formação desportiva, pela inexistência das necessárias condições de recuperação e de descanso que indivíduos em processo de crescimento acentuado exigem.

Não pode, pois, deixar de pensar-se a organização da carga de treino à luz destas realidades. A tendência para o sistemático aumento do tempo consagrado à preparação no desporto de rendimento deve ser invertida, de acordo com prioridades em que a preparação desportiva não pode desempenhar ainda um papel essencial. Os resultados no alto nível cada vez mais dependem do que se fez nos anos da formação e não do número de anos passados na preparação.

Torna-se por isso necessário equacionar, na organização do sistema de cargas, um papel de maior relevância da qualidade dos estímulos, por contraposição a uma tendência em que a prioridade é atribuída à quantidade de treino. Substituir a quantidade, pela qualidade, como orientação dominante.

Tal como aconteceu há alguns anos no desporto de alto rendimento, não deve esperar-se, também no desporto dos mais jovens, que a evolução das condições que promovem o potencial dos jovens desportistas dependa no essencial do aumento do tempo consagrado à preparação.

Significa isto, então, o quê? Que deveremos substituir uma opção centrada no volume, por uma outra centrada na intensidade? Não, antes que deveremos pensar mais na qualidade dos estímulos de treino e menos na sua quantidade. Ou, como diz Martin (32), para um mesmo tempo de treino deveremos promover uma maior qualidade de intervenção, através de cargas e conteúdos criteriosamente escolhidos.
Estamos manifestamente perante um quadro insuficiente. Não basta definir qual o volume e a intensidade das cargas. É preciso conferir uma orientação mais precisa às cargas, para além das normas de orientação geral. Não havendo na preparação cargas em abstracto, importa definir outras regras, mais concretas.

Como avançar no sentido de definir modelos de organização da carga que contribuam para promover o desenvolvimento dos mais jovens e construir de forma mais efectiva as condições que garantirão níveis de rendimento cada vez mais elevados no futuro? Por um lado, construindo o modelo teórico de organização da carga em estreita associação com o "princípio da preparação para altas cargas" (2). Isto é:

(i) construindo uma base sólida para os rendimentos futuros através de um adequado desenvolvimento das condições de cargabilidade geral durante as primeiras fases da formação; que permita, mais tarde, elevar as cargas a níveis que respondam por aumentos significativos da prestação e, por outro lado, minimizar o impacte dessas cargas sobre as estruturas corporais; e

(ii) potenciando os efeitos das cargas gerais de treino na elevação do nível da capacidade de prestação especializada.

Por outro lado, e esta é uma tendência que se vai afirmando cada vez mais, apontando para a necessidade de melhoria da qualidade das cargas de treino.

Melhorar a qualidade das cargas? O que pode isto significar? Escolher e valorizar conteúdos e estímulos de treino cujas características se constituam em pressupostos da maximização das futuras prestações desportivas.

Que pressupostos são esses? Que estratégias introduzir no treino que assegurem condições de maior eficácia alguns anos mais tarde?

Há componentes da estrutura da prestação que, apesar de influenciarem de forma determinante o rendimento de alto nível em cada desporto, não são objecto de um desenvolvimento adequado durante a formação. Se isto não acontecer nestas fases dificilmente poderá acontecer mais tarde. O que limita as possibilidades de abertura de novas 
reservas de rendimento. A sua identificação e a definição dos momentos mais adequados para o desenvolvimento dessas componentes, constituemse em pressupostos da promoção de um treino de qualidade (2).

A Teoria da Acção (cf. 48) apoia-se na necessidade de uma concepção unitária no desenvolvimento da actividade, como pressuposto da construção de uma prestação que é complexa. Determinando a realização sistemática e integrada do treino a partir da valorização de todas as componentes - motoras, bioenergéticas e informacionais - que fazem a estrutura da prestação, a partir de processos de regulação cognitivos, volitivos e emocionais. $\mathrm{Na}$ prática as coisas passam-se de forma diferente. A Lei do Estímulo/Adaptação dos sistemas bioenergéticos (2) continua a marcar o que de essencial faz o foco da actividade de treino numa grande maioria das actividades desportivas. Relegados para um plano claramente secundário estão os processos informacionais. O que tem manifestas consequências no processo de formação, um tempo de crucial importância nas tarefas da aprendizagem.

Sem contrariar os pressupostos que atrás apresentámos no âmbito da Teoria da Acção, mas valorizando orientações que decorrem de lógicas próprias de cada momento da preparação, entendemos que antes da puberdade as prioridades do treino se voltem para a dimensão informacional, cognitiva e coordenativa - da actividade e após este período seja mais valorizada a dimensão condicional - bioenergética e funcional - da actividade desportiva.

Em concreto, julgamos que este debate sobre a promoção da qualidade se centra hoje sobre três eixos centrais $(2,30,32)$ :

(i) o aperfeiçoamento da formação técnica desportiva;

(ii) a revalorização da tomada de decisão nas acções desportivas; e

(iii) a qualificação do treino de velocidade.

\section{AS CAPACIDADES MOTORAS}

As capacidades motoras são componentes do rendimento e, desta forma, conteúdos essenciais aos programas de treino dos jovens. Porém, o debate teórico acerca do seu desenvolvimento tem-se centrado mais nas questões que condicionam o seu nível de expressão - como, por exemplo, o efeito do crescimento e da maturação, ou a sua treinabilidade - e menos nas estratégias de treino a longo prazo. A discussão destas tem-se apoiado, sobretudo, no conhecimento empírico e em experiências da prática dos treinadores.

Do conhecimento actual emergem tendências metodológicas que visam a racionalização do processo de treino, pela melhoria da sua efectividade, em resposta às necessidades da especialização.

Em abstracto, as capacidades motoras são consideradas a base de uma hipotética pirâmide composta por todas as componentes do rendimento (15). De acordo com este entendimento, o desempenho de tarefas de incidência técnica ou táctica teria sempre na sua base exigências de resistência, força, velocidade e/ou flexibilidade (a). Porém, nem sempre a lógica funcional alinha pela lógica pedagógica. Se assim fosse, seria natural que o desenvolvimento das capacidades motoras constituísse o conteúdo fundamental da preparação dos mais jovens, traduzido num maior volume registado em treino. O que nem sempre se verifica (21). O treino da técnica sempre foi um conteúdo fundamental da formação dos mais jovens. Esta tendência tem-se reforçado através da integração de complexos de competições técnicas no sistema de competições. A valorização da técnica decorre precisamente do facto de só poder haver especialização quando o praticante se apropria do reportório de instrumentos que são eficientes para a resolução de uma tarefa motora específica (34). A característica eficiência remete, em primeiro lugar, para os aspectos da regulação e controlo motor, pelo grau de condicionamento que estes estabelecem ao nível da justeza da execução face a um padrão. A importância da técnica, no contexto global do rendimento desportivo, não é idêntica em todas as modalidades (16).

São igualmente conhecidos os factores que determinam a oportunidade de utilização das técnicas das várias modalidades desportivas. Em certas modalidades, como os jogos desportivos, a técnica 
representa o instrumento para resolver situações de jogo (11). A escolha de uma técnica depende de um juízo prévio acerca da utilidade e oportunidade do seu emprego. A natureza destas modalidades, consideradas desportos de situação (18), faz ressaltar a importância do factor decisão (o que fazer?), mas também, face às características de contexto variável, a necessidade de adaptação (como fazer?).

Torna-se, assim, necessário repensar a formação da técnica, valorizando o treino da regulação e controlo do movimento num quadro de exigências que influenciem de forma mais efectiva esta componente que é decisiva na formação (2). O que pressupõe investigação e desenvolvimento do conhecimento sobre:

(i) a formação da técnica desportiva em domínios como os do processamento da informação, representação e programação motora,

(ii) formas de abordagem da técnica, por exemplo, em situações de elevada interferência contextual $(13,34) \mathrm{e}$

(iii) a relação de integração com os factores que nos planos condicional e/ou decisional condicionam de forma essencial os desempenhos desportivos.

Deste modo, numa lógica estritamente pedagógica, o desenvolvimento das capacidades motoras fica subordinado à prioridade estratégica que é concedida à formação da técnica desportiva. O que não pretende significar a desvalorização do treino das capacidades motoras. Antes pelo contrário, ele deve contribuir para acelerar o desenvolvimento técnico. Ao treino da velocidade no desporto de jovens tem sido devotada grande atenção. Os factores associados aos limites da expressão desta capacidade têm vindo a ser estudados pela comunidade científica, quer em adultos quer em jovens. Nestes últimos, porém, condicionamentos éticos à utilização de métodos e instrumentos tornam o conhecimento mais limitado, pese embora o seu avanço (20).

De entre os factores que condicionam a velocidade, os aspectos neurais surgem mais precocemente associados ao desenvolvimento das prestações em pré-puberes e puberes, até sensivelmente o meio da adolescência $(3,17,20)$. Outros factores, como os musculares e metabólicos, parecem ganhar importância em fases mais tardias da puberdade. Não quer isto significar que também estes factores não possam ser influenciáveis pelo treino em fases mais precoces do processo de crescimento e maturação. Tal terá sido mesmo já comprovado $(8,6,10,39)$.

A força vem ganhando espaço e importância no treino dos mais jovens. Uma solicitação mais precoce tem contribuído para uma formação especializada de maior qualidade.

Ultrapassada a polémica sobre a treinabilidade da força em sujeitos pré-púberes $(4,7,12,39,43,51) \mathrm{e}$ identificados os mecanismos associados aos ganhos da força com o treino $(4,35,39,50)$ - essencialmente por adaptação neural nos pré-púberes e também por adaptação miogénica em adolescentes -, importa perceber quais os métodos e meios apropriados para o seu desenvolvimento.

No treino da velocidade e da força, nem sempre a ênfase tem sido colocada nos factores mais importantes. Recordemos o que atrás dissemos. No processo de formação de jovens praticantes desportivos a lógica pedagógica deve sobrepor-se à lógica funcional. Por este motivo, a prioridade deverá ser colocada ao nível das competências coordenativas específicas, isto é, das técnicas desportivas. Desta forma, o treino da velocidade e da força devem concorrer para a melhoria da expressão da técnica, e esta para o desenvolvimento daquelas. De facto, diversos estudos (3) comprovam que, antes mesmo do incremento do potencial de activação das unidades motoras, os ganhos de velocidade e de força resultam do desenvolvimento da coordenação motora, ou seja, do aperfeiçoamento da coordenação entre músculos sinergistas e entre agonistas e antagonistas. Pode então concluir-se que a formação e o aperfeiçoamento da técnica concorrem directamente para o desenvolvimento da força e da velocidade. $\mathrm{O}$ que deve ter consequências nas estratégias de treino: mais do que promovermos exigências gerais de velocidade ou de força, deveremos centrar-nos na melhoria da coordenação motora dos gestos e acções desportivas, fazendo progressivamente um aumento das exigências de velocidade e de força. Numa outra perspectiva, a velocidade é o resultado da melhoria da percepção dos estímulos e do processamento da informação $(9,44)$. A aprendizagem de habilidades e a consciência resultante da aprendizagem 
e do armazenamento em memória das situações que condicionam a acção ou o movimento, são assim factores que confluem para o aumento da velocidade da execução, pela redução do tempo de reaç̧ão. Podemos ainda considerar a execução da técnica desportiva em situação de elevada interferência contextual. No caso, o sucesso da prestação dependerá da capacidade de repartir a atenção entre a tarefa motora e as exigências cognitivas. O que está associado, primariamente, à forma como é adquirida e tratada a informação, mas também ao tempo útil de execução. Então, as fases de aquisição da informação, da programação motora e da reacção são importantes factores de ordem neural, a considerar com prioridade.

O desenvolvimento de adaptações neurais, visando o desenvolvimento qualitativo das acções motoras em tarefas que exigem resposta rápida, deverá fazer-se em situações de intensidade máxima ou quase máxima e de grande complexidade, isto é, com

\section{NOTAS}

(a) A omissão das capacidades coordenativas no tratamento das capacidades motoras, resulta do facto de se considerar que a técnica corresponde a uma forma especializada da coordenação. Neste sentido, as capacidades coordenativas gerais estão ligadas aos movimentos básicos que se supõem adquiridos quando do início da especialização desportiva.

\section{REFERÊNCIAS}

1. Andrade MG (1995). Para uma teoria das competições desportivas em crianças e jovens. Dissertação de mestrado. Faculdade de Ciências do Desporto e de Educação Física, Universidade do Porto.

2. Bauersfeld KH (1991). Tendenzen der Weiterentwicklung des Kinder- und Jugendtrainings. In: Kirchgässner H (ed.). 40 Jahre Deutsche Hochschule für Körperkultur Leipzig.

Academia Verlag Sankt Augustin,: 82-92.

3. Blimkie CJR, Bar-Or O (1996). Treinability of muscle strength, power and endurance during childhood. In: Bar-Or O (ed). The child and adolescent athlete. London: Blackwell Science, 113-117.

4. Blimkie CJR, Ramsay J, Sale D, MacDougall D, Smith K, Garner S (1989). Effects of 10 weeks of resistance training on strength development in prepubertal boys. In: Oseid S. e Carlsen K-H. (eds.). Children and Exercise XIII, Champaign, IL: Human Kinetics, 183-197

5. Bremer D (1986). Wettkampfsport im Grundschulalter. Leistungssport 2: 5-10 pressão de tempo.

No caso da força aplicada a um movimento, as intensidades máximas referem-se sobretudo à componente força inicial, o que pressupõe resistências ligeiras e velocidades de movimento máximas (42).

Sabe-se que o aumento da velocidade da resposta e da execução motora, assim como o aumento das exigências de força aplicada num movimento aumentam as possibilidades de ocorrência de erro. Torna-se então necessário promover nas fases adequadas, não apenas um treino geral orientado de velocidade e de força, mas o treino da técnica em regime de velocidade e de força e em situações próximas do contexto da actividade.

Percebe-se assim melhor porque é também a coordenação o produto da força e da velocidade (14). Contudo, este tipo de treino, obriga a uma dupla preocupação: a de conciliar a intensidade com a correcção do movimento.
6. Cadefau J, Casadmont J, Grau JM, Fernandez J, Balaguer A, Vernet M, Cusso R, Urbano-Marquez A (1990). Biochemical and histochemical adaptations to sprint training in young athletes. Acta Physiol Scand 140: 341-351

7. Clarke DH, Vaccaro P, Andersen N. Physiological alterations in 7- to 9-year-old boys following a season of competitive wrestling. RQES 55 1984: 318-322

8. Eriksson BO, Gollnick PD, Saltin B (1973). Muscle metabolism and enzyme activities after training in boys 11-13 years old. Acta Physiol Scand 87: 485-497

9. Fagard J (1996). Skill acquisition in children: historical perspective. In: Bar-Or O (ed). The child and adolescent athlete. London: Blackwell Science, 74-91

10. Fournier M, Ricci J, Taylor AW, Ferguson RJ, Montpetit RB, Chaitmen BR (1982). Skeletal muscle adaptation in adolescent boys: sprint and endurance training and detraining. Med Sci Sports Exerc 14: 453-456

11. Garganta J (1997). Modelação táctica no jogo de futebol. Estudo da organização da fase ofensiva em equipas de alto 
rendimento. Tese de Doutoramento. Porto: Faculdade de Ciências do Desporto e de Educação Física, Universidade do Porto 12. Gillam GM (1981). Effects of frequency of weight training on muscle strength enhancement. J Sports Med Phys Fitness 21: $432-436$

13. Graça A (1994). Os comos e os quandos no ensino dos jogos. In: O ensino dos jogos desportivos. Graça A e Oliveira J (eds.), Centro de Estudos dos Jogos Desportivos, Porto: Faculdade de Ciências do Desporto e de Educação Física, Universidade do Porto, 27-34

14. Grosser M, Neumaier A (1986). Técnicas de

Entrenamiento. Barcelona: Edicionez Martínez Roca SA.

15. Harre D (1982). Principles of sport training. Berlin: Sportverlag

16. Hegedus J (1980). El entrenamiento técnico: sus distintos procesos. Stadium 84: 16-23

17. Inbar O (1996). Development of anaerobic power and local muscular endurance. In: The child and adolescent athlete. BarOr O. (ed.), London: Blackweel Science, 42-53

18. Konzag I (1991). A formação técnico-táctica nos jogos desportivos colectivos. Treino Desportivo 19, II série: 27-37 19. Kurz D (1988). Pädagogische Grundlagen des Trainings. Studienbrief 4 der Trainerakademie Köln, Hofmann-Verlag, Schorndorf

20. Mahon AD (2000). Exercise training. In: Paediatric Exercise Science and Medicine. Armstrong $\mathrm{N}$ e van Mechelen W. (eds.). Oxford: Oxford University Press, 201-222 21. Marques A, Maia J, Oliveira J, Prista A (1999). Training Structure of Portuguese Young Athletes. In: Abstract Book of the Conference on Youth Sports in the 21st Century:

Organized Sport in Lives of Children and Adolescents. East Lansing - USA: Michigan State University, 67-68

22. Marques A (1985). A Carreira Desportiva de um Atleta de Fundo. Horizonte 9: 84-89

23. Marques A (1991). A Especialização Precoce na Preparação Desportiva. Treino Desportivo 19: 9-15

24. Marques A (1993). A periodização do treino em crianças e jovens. Resultados de um estudo nos centros experimentais de treino da Faculdade de Ciências do Desporto e de Educação Física da Universidade do Porto. In: Bento J, Marques A (ed.) A Ciência do Desporto, a Cultura e o Homem. Faculdade de Ciências do Desporto e de Educação Física da Universidade do Porto, Câmara Municipal do Porto, 243-258

25. Marques A (1997). A preparação desportiva de crianças e jovens. O sistema de competições. In: Guedes O (org.) Atividade Física: uma abordagem multidimensional. João Pessoa: Ideia, 157-169

26. Marques A (1999). Crianças e adolescentes atletas: entre a escola e os centros de treino... entre os centros de treino e a escola. In: Adelino J, Vieira J, Coelho O (ed.) Treino de Jovens. Lisboa: CEFD, Secretaria de Estado do Desporto, 17-30 27. Marques A (1995). O desenvolvimento das capacidades motoras na escola. Os métodos de treino e a teoria das fases sensíveis em questão. Horizonte 66: 212-216

28. Marques A (1989). Sobre a Utilização dos Meios de Preparação Geral na Preparação Desportiva (I). Treino Desportivo 14: 18-24

29. Marques A (1990). Sobre a Utilização dos Meios de Preparação Geral na Preparação Desportiva (II). Treino Desportivo 15: 55-61

30. Marques A (2000). Sobre as questões da qualidade no treino dos mais jovens. In: Francisco Martins da Silva (org.) Produção do conhecimento no treinamento desportivo. Pluralidade e diversidade. João Pessoa: Editora Universitária, UFPB, 51-59 31. Martin D, Carl K, Lehnertz K (1993). Manuale di Teoria dell'Allenamento. Roma: Società Stampa Sportiva

32. Martin D (1991). Zum Belastungsproblem im Kinder- und Jugendtraining unter besonderen Berücksichtung von Vielseitigkeit oder Frühspezialisierung. In: Kirchgässner H (ed.) 40 Jahre Deutsche Hochschule für Körperkultur Leipzig. Academia Verlag Sankt Augustin, 115-123

33. Martin D (1999). Capacidade de performance e desenvolvimento no desporto de jovens. In: Adelino J, Vieira J, Coelho O (ed.). Treino de Jovens. Lisboa: CEFD, Secretaria de Estado do Desporto, 37-59.

34. Mesquita I (1998). A instrução e a estruturação das tarefas no treino de voleibol. Estudo experimental no escalão de iniciados feminino. Tese de Doutoramento. Porto: Faculdade de Ciências do Desporto e de Educação Física, Universidade do Porto 35. Ozmun JC, Mikesky AE, Surburg PR (1994).

Neuromuscular adaptations following prepubescent strength training. Med Sci Sports Exerc 26: 510-514

36. Petlichkoff L (1996). The drop-out dilemma in Youth Sports. In: Bar-Or O. (ed.). The Child and Adolescent Athlete. Oxford: Blackwell Science, 418-430

37. Platonov VN (1988). L'Entraînement Sportif. Théorie et Méthodologie. Paris: Éditions EPS

38. Rahn S (1993). Zu einigen Problemen des allgemeinen trainings bei der Entwicklung von Leistungsvoraussetzungen im Nachwuchsleistungssport. In: Lenz J, Nietzsche K, Polster $\mathrm{H}$ (ed.) Leistungsvoraussetzungen im Nachwuchstraining. Academia Verlag Sankt Augustin, 16-25.

39. Ramsay JR, Blimkie CJR, Smith K, Garner S, MacDougall JD, Sale DJ (1990). Strength training effects in prepubescent boys. Med Sci Sports Exerc 26: 605-614

40. Robertson I (1986). Youth Sport in Australia. In: Weiss M, Gould D (eds.). Sport for Children and Youths. The 1984 Olympic Scientific Congress Proceedings vol. X. Champaign, Illinois: Human Kinetics Pubs, 5-10

41. Rost K (1995). Le Gare nello Sport Giovanile. SdS 32: 69-73 42. Schmidtbleicher D (1996). O treino da força e da potência em atletas de alto rendimento. Texto de apoio ao curso satélite do ISBS'96, 22 e 23 de Junho de 1996, Lisboa: FMH - UTL 43. Sewall L, Micheli LJ (1986). Strength training for children. Journal Pediatric Orthopedics 6: 143-146

44. Tavares F (1993). A Capacidade de decisão táctica no jogador de basquetebol. Tese de Doutoramento. Porto: Faculdade de Ciências do Desporto e de Educação Física, Universidade do Porto

45. Thieß G (1991). Das Nachwuchstraining im Spigel von 20 Jahren "Leistungssport". Fortschritte und Defizite.

Leistungssport 6: 12-14

46. Thieß G (1995). Die Ausarbeitung einer "Wettkampflehre hat begonnen. Leistungssport 1:5

47. Tschiene P (1995). Adaptive Aspekte des Wettkampfs. Leistungssport 1: 16-19

48. Tschiene P (1988). Der qualitative ansatz zu einer Theorie des Trainings. Leistungssport 3: 8-11

49. Tschiene P (1989). Die neue "Theorie des Trainings" und ihre interpretation für das Nachwuchstraining. Leistungssport 4: 11-17 50. Vrijens J (1978). Muscle strength development in pre- and post-pubescent age. Med Sport 11: 152-158

51. Weltman A, Janney C, Rains CB, Strand K, Berg B, Tippit S Wise J, Cahill BR, Katch FI (1986). The effect of hydraulic resistance strength training in pre-pubertal males. Med Sci Spots Exerc 18: 629-638 